\title{
Perceived Autonomy Support Egzersizde Alg1lanan Scale for Exercise Settings: Özerklik Desteği Ölçeği: Validity and reliability study Türkçe geçerlik ve güvenirlik for Turkish çalışması $^{1}$
}

\author{
Mine Müftüler²
}

\begin{abstract}
The purpose of this study was to examine the validity and reliability of Perceived Autonomy Support Scale for Exercise Settings (PASSES; Hagger et al., 2007) from teacher and from peers in Turkish context. It was conducted with volunteer university students. 230 university students completed PASSES from teacher, and 142 university students completed PASSES from peers. Each scale has 12 items with a unidimension structure. The items were rated on a 7-point Likert type scale from totally disagree (1) to totally agree (7). Each scale was analyzed by using confirmatory factor analysis (CFA) to determine validity and by using Cronbach alpha value to determine reliability. The validity analyses for each scale showed good fit indexes in Turkish context. The reliability analyses also showed high reliability scores for each scale. Results were consistent with previous studies. It was suggested that PASSES from teacher and from peers can be used in Turkish context.
\end{abstract}

Keywords: Perceived Autonomy Support In Exercise; Teacher; Peers; Validity And Reliability.

(Extended English abstract is at the end of this document)
Özet

$\mathrm{Bu}$ araştırmanın amac1 "Egzersizde Algılanan Özerklik Desteği Ölçeğinin" (Perceived Autonomy Support Scale for Exercise Settings; Hagger ve diğ., 2007) hem öğretmen hem de arkadaşlar versiyonunu Türkçeye uyarlamak ve her iki ölçeğin geçerlik ve güvenirliğini incelemektir. $\mathrm{Bu}$ amaçla Türkçeye çevrilen ölçekler bir grup üniversite öğrencisine uygulanmıştır (öğretmen versiyonu için $n=230$; arkadaşlar versiyonu için $n=142$ ). Tek boyutlu olan ölçekler 12 ifadeden oluşmaktadır ve ifadeler tamamen katilmiyorum (1)'dan tamamen katıliyorum (7)'a doğru siralanan yedili Likert üzerinden değerlendirilmektedir. Ölçeğin yapı geçerliğini belirlemek için doğrulayıcı faktör analizi uygulanmış, iç güvenirliğini tespit etmek için de Cronbach alfa kat sayısı hesaplanmıştır. Her iki ölçeğin yapı geçerliği bulguları iyi uyum indeksleri göstermiştir. Her iki ölçeğin iç güvenirlik kat sayıları da oldukça yüksek olarak hesaplanmıştır. Elde edilen bulgular alan yazında ilgili araşturmalarla benzerlik göstermektedir. Egzersizde Algılanan Özerklik Desteği Ölçeğinin hem öğretmen hem de arkadaşlar versiyonunun Türkçede ilgili araştırmalarda kullanılabileceği önerilmektedir.

Anahtar Kelimeler: Egzersizde Algilanan Özerklik Desteği; Öğretmen; Arkadaşlar; Geçerlik ve Güvenirlik.

\footnotetext{
${ }^{1}$ This paper was presented as a poster presentation in the $2^{\text {nd }}$ International Social Sciences in Physical Education and Sport Congress in Gazi University (31 May-2 June 2012).

2 Yrd. Doç. Dr., Muğla Sitk1 Koçman Üniversitesi, Spor Bilimleri Fakültesi, Rekreasyon Bölümü, minemuftuler@mu.edu.tr
} 
Müftüler, M. (2016). Egzersizde Alg1lanan Özerklik Desteği Ölçeği: Türkçe geçerlik ve güvenirlik çalışması. International Journal of Human Sciences, 13(1), 2158-2169. doi:10.14687/ijhs.v13i1.3653

Giriş

Öz-belirleme kuramı (ÖBK) bireylerin davranışlarının psikolojik süreçlerini açıklayan güdülenme kuramıdır (Deci ve Ryan, 1985). Bu kuramda bireyin davranışlarının başkaları tarafından kontrol edilmesinden ziyade özerkliği desteklendiğinde daha olumlu davranışlar sergilediği belirtilmektedir. $\mathrm{Bu}$ kurama göre bireyin davranışlarının şekillenmesi için temel psikolojik ihtiyaçlarının giderilmesi gerekmektedir. Temel psikolojik ihtiyaçlar yeterlik, ilişkili olma ve özerklik ihtiyaçlarıdır (Deci ve Ryan, 1987). Yeterlilik ihtiyacı, sergilenen davranış veya eylemde bireyin kendini yeterli hissetmesi ve çevresiyle etkili bir şekilde iletişime geçebilme kapasitesidir. İliskili olma ihtiyac1, bireyin çevresindeki önemli kişilerle sosyal bir ilişki içerisinde olma ve kendini sosyal çevreye ait hissetme ihtiyacı anlamına gelmektedir. Özerklik ihtiyacı ise bireyin davranışlarını olduğu gibi kabul etmesi ve kendi kararlarını kendisi vermesi olarak tanımlanır (Deci ve Ryan, 1987). Bir başka deyişle özerklik bireyin içsel olarak odaklanması ve bilinçli güdülenme kapasitesidir. Örneğin bir birey kendi ilgi alanı ve merakı doğrultusunda davranışlarını sürdürdüğünde ve bilinçli olarak kendini güdülediğinde özerk davranışlar sergilemiştir.

Bireyin özerk olarak davranabilmesi için çevre koşullarının ve diğer bireylerin de özerkliği destekleyici unsurlar içermesi önemlidir. Çevreden sağlanan özerklik desteği, bireyin içsel güdülenmesini desteklemekte, tüm potansiyelini sergilemesini sağlamakta ve kendi ilgi ve isteklerine ulaşmasına yardımcı olmaktadır (Andersen, 2000). Özerklike desteğ ilgi, amaç ve değerler gibi içsel güdülenme kaynaklarını tespit etmesi, yetiştirmesi ve geliştirmesini sağlayan kişilerarası destek anlamına gelmektedir (Reeve ve Jang, 2006). Özerklike desteğ̈i, bir öğretmenin öğrencilerini derse hazırlıklı gelmesi ve ders içi etkinliklere katılımlarını artırmak için öğrencilerinin içsel güdülerini teşvik etmesi olarak örneklendirilebilir. Algzlanan özerklike desteği ise bireylerin, özerklik destekleyici konumunda olan kişilerin özerklik desteği davranışlarını algılama derecesi olarak tanımlanmışır (Deci ve Ryan, 1987). Bir başka deyişle öğrencilerin, öğretmenlerinin özerklik destekleyici davranışlar sergilemesini algilamasıdır.

Alan yazında yapılan araştırmalar, özerklik desteği konusunun eğitimden psikoterapiye farklı alanlarda araştırldığını göstermiştir. Farklı alanlardaki özerklik desteği kaynakları Tablo 1'de özetlenmiştir.

Tablo 1. Farklı alanlarda özerklik desteği kaynakları

\begin{tabular}{ll}
\hline Alan & Kaynak \\
\hline Ĕ̆itim & Öğretmen / Ĕ̈itmen \\
Beden eğitimi, spor veya egzersiz & Antrenör / Beden eğitimi öğretmeni / Akran / Anne-baba \\
İş & Yönetici / Müdür \\
Sağllk bakımı & Doktor / Fizyoterapist \\
Psikoterapi & Psikoterapist \\
\hline
\end{tabular}

Yukarıda ki tablodan da anlaşılacağı üzere bireye özerklik desteğini sağlayan farklı kaynaklar bulunmaktadır. Eğitim alanında yapılan çalışmalar öğretmenin öğrencilere özerklik desteği sağlayan en önemli kaynak olduğunu göstermiştir (Reeve, Bolt ve Cai, 1999; Reeve, 2006). Eğitim ortamında öğretmenin öğrenme etkinliklerinde açıklayıcı olması, öğrencilerin bakış açısını dikkate alması, kontrol edici olmayan anlatım dilini kullanması, seçenekler sunması ve öğrencilerin içsel güdülenmesini teşvik etmesi en belirgin özerklik destekleyici davranışlar arasındadır ( $\mathrm{Su}$ ve Reeve, 2011).

Geçmiş yıllarda yapılan araştırmalar özerklik desteği sağlayan öğretmenlerin öğrencilerinin sınıf içi etkinliklere katılımı ve yaratıcılı̆̆ının arttı̆̆ı, daha yüksek akademik başarı ve performansa sahip olduğunu ve benzeri birçok eğitimsel ve psikolojik edinime sahip olduklanın göstermiştir. Örneğin Grolnick ve Ryan (1987), öğretmenlerinden özerklik desteği alan ilköğretim öğrencilerinin daha özerk davrandıklarını ve daha uyumlu davranışlar sergilediğini göstermiştir. Aynı zamanda özerklik desteği sağlayan öğretmenler öğrencilerinin içsel güdülenmesini arttırmakta (Deci ve Ryan, 
Müftüler, M. (2016). Egzersizde Algilanan Özerklik Desteği Ölçeği: Türkçe geçerlik ve güvenirlik çalsşması. International Journal of Human Sciences, 13(1), 2158-2169. doi:10.14687/ijhs.v13i1.3653

1987; Ryan ve Deci, 2000) ve olumlu akademik yeterlik algisına sahip olmaya katkıda bulunmaktadır (Guay, Boggiano ve Vallerand, 2001). Yapılan araşturmalar, özerkliği desteklenmiş öğrencilerin eğitim ortamında daha başarılı olduklarını göstermiştir (Reeve, 2002).

Türkiye'de de son yıllarda öğretmenlerin özerklik desteğine ilişkin araştırmalar yapılmıştır. Ancak bunların büyük bir çoğunluğu yabancı dil öğrenimi üzerine yapılmış çalışmalardır (Aydoğdu, 2009; Balçıkanl1, 2008; Sert, 2006; 2007; Üstünoğlu, 2009). Özetle bu çalışmalar yabanc1 dil öğretmenlerinin öğrencilerine özerklik destekleyici unsurları sağlamadığını göstermiştir. Sınıf öğretmenleriyle yapılan başka araşturmalarda ise öğretmenlerin öğrencilerine özerklik desteği sağlamaya ilişkin görüşleri incelenmiştir. Bu çalş̧malarda öğretmenlerin genel olarak özerklik destekleyici davranışları gerekli bulduğu (Oğuz, 2013) ancak öğretmenlerin özerklik desteğinin orta seviyede olduğu (Güvenç, 2011) ortaya çıkmıştır. Üniversitede okuyan öğrenciler üzerinde yapılan bir başka araşturmada ise öğretmenden kaynaklanan özerklik desteği alan öğrencilerin yüksek derecede içsel güdülenmeye sahip oldukları tespit edilmiştir (Özgüngör, 2006).

Beden eğitimi, spor ve egzersiz alanlarında da özerklik desteği sağlayan farklı kaynaklar mevcuttur. Beden eğitimi alanında beden eğitimi öğretmeni önemli bir özerklik desteği kaynağıdır (Hagger ve dĭg., 2007). Beden eğitimi öğretmeninden kaynaklanan algilanan özerklik desteği beden eğitimi dersinde öğrenmeyi (Shen ve diğ., 2009) ve derse katılımı (Shen, 2010) artırmış ve öğrencileri fiziksel aktiviteye katılıma dair daha özerk davranmaya teşvik etmiştir (Lim ve Wang, 2009). Daha güncel yapılan deneysel yapıdaki bir araştırmada ise özerklik-destekleyici uygulamanın öğrencilerin ders içi güdülenmesine etkisi incelenmiştir (Cheon, Reeve ve Moon, 2012). Elde edilen bulgular özerklik-destekleyici uygulama alan beden eğitimi öğretmenlerinin ders içinde daha çok özerklikdestekleyici davranışlar sergilediğini ve bunun da öğrencilerin temel psikolojik ihtiyaçlarının karşılanmasında, içsel güdülenme, derse katılım, beceri gelişimi ve akademik başarının artmasında etkisi olduğunu göstermiştir.

Spor alanında sporculara özerklik desteği sağlayan en önemli kaynak ise antrenördür (Mageau ve Vallerand, 2003). Antrenörden kaynaklanan özerklik desteği alg1sı sporcunun olumlu güdülenmesine, daha fazla psikolojik ihtiyaç doyumuna ve daha başarllı sportif performansa etki etmektedir (Amorose ve Anderson-Butcher, 2007; Gillet, Vallerand, Amoura ve Baldes, 2010a).

Bireylerin serbest zamanlarında katıldıkları egzersiz ortaminda egzersiz uzmanı veya eğitmeninin (Moustaka ve diğ., 2012) yanı sıra arkadaşlar ve anne-baba da (Hagger ve diğ., 2009) önemli bir özerklik desteği kaynağıdır. Alan yazında yer alan ilişkisel çalışmalar egzersiz uzmanı veya eğitmenden kaynaklanan algılanan özerklik desteğinin egzersiz katılımcılarını daha fazla güdülediğini belirtmektedir (Edmunds, Ntoumanis ve Duda, 2006; Puente ve Anshel, 2010). Arkadaşlar veya anne-babadan kaynaklanan özerklik desteği ise serbest zaman fiziksel aktiviteye katılıma dair içsel güdülenmeye olumlu etki eden diğer kaynaklardır (Hagger ve diğ., 2007; 2009).

Alan yazında son on yılda beden eğitimi, spor ve egzersiz alanlarında algılanan özerklik desteğinin önemi, öğrenci veya sporcunun güdülenme süreçlerine ve performansına etkisini inceleyen çeşitli çalışmalar yer almaktadır. Deneysel araştırma niteliğinde yürütülen bir araştırmada algılanan özerklik desteği kavramını içeren Bağlamlararası modele dayalı eğitimin üniversite öğrencilerinin serbest zaman fiziksel aktivite katılımına etkisi incelenmiştir (Müftüler ve İnce, 2015). Elde edilen bulgular özerklik destekleyici bir ortamda eğitim alan üniversite öğrencilerinin hem eğitmenden hem de arkadaşlardan kaynaklanan algılanan özerklik desteğini artırdığını, serbest zaman fiziksel aktiviteye katıllıma dair güdülenmeyi ve olumlu niyeti desteklediğini ve egzersizde psikolojik ihtiyaç doyumunun artmasını sağladığını göstermiştir.

Tüm bu bilgiler doğrultusunda algılanan özerklik desteği kavramının hem eğitim hem de spor ve egzersiz alanlarının yanı sıra çeşitli alanlarda da kullanıldığı ortaya çıkmıstır. Bahsi geçen kullanım alanlarına göre algılanan özerklik desteği kaynakları da farklılık göstermektedir. Bunun yanı sıra, algılanan özerklik desteği kavramı farklı kültürlerde de incelenmiştir. İngiltere, Yunanistan, Polonya, Estonya, Macaristan, Finlandiya ve Singapur gibi farklı kültürlerde yapılan kültürler-arası karşılaştırma niteliğindeki çalışmalar, algılanan özerklik desteği kavramının genellenmesini 
sağlamıştır (Barkoukis, Hagger, Lambropoulos ve Tsorbatzoudis, 2010; Hagger ve diğ., 2005; 2007; 2009). Ancak ülkemizde yapılan benzer çalışmalara da ihtiyaç duyulmaktadır.

Alan yazında, algılanan özerklik desteğinin ölçülmesi için güvenirliği tespit edilmiş bir dizi ölçeğe rastlanmaktadır. Ölçekler, kullanıldıkları alanlara ve özerklik desteği sağlayan kaynağa göre çeşitlilik göstermektedir. Mesela sağlık alanında sağlık bakımı sağlayan kişiyi değerlendiren (Williams, Cox, Kouides ve Deci, 1999), öğrenme ortamında eğitmeni değerlendiren (Black ve Deci, 2000), iş ortamında yöneticiyi değerlendiren (Baard, Deci ve Ryan, 2004), egzersiz ve spor ortamında antrenörü değerlendiren (Gillet, Vallerand, Paty, Gobance ve Berjot, 2010b) farklı ölçekler mevcuttur.

Hagger ve diğ. (2007) Egzersizde Alg1lanan Özerklik Desteği Ölçeğini (Perceived Autonomy Support Scale in Exercise Settings - PASSES) geliştirmiş ve yapı geçerliğini tespit etmiştir. Yapılan bu çalışmada katulımcılar hem beden eğitimi öğretmeni hem de arkadaş ve annebabadan kaynaklanan alg1lanan özerklik desteğini değerlendirmiştir. Elde edilen bulgular, Egzersizde Alg1lanan Özerklik Desteği Ölçeğinin geçerli ve güvenilir bir ölçek olduğunu göstermiştir (Hagger ve diğ., 2007). Bu ölçek, öğrencilerin veya bireylerin egzersiz ortamında önemli kişilerden kaynaklanan (beden eğitimi öğretmeni, arkadaş, anne-baba vb.) özerklik desteği algısını değerlendirmek için oluşturulmuştur. Algılanan özerklik desteği kavramı farklı kültürlere genellenebildiği için başka dillere çevrilmiş ve geçerliği tespit edilmiştir (Gillet ve diğ., 2010b; Moreno, Parra ve González-Cutre, 2008). Yapılan araştırmalarda bu ölçeğin beden eğitimi öğretmenini değerlendirmek için (Barkoukis ve diğ., 2010), arkadaşlar ve anne-babay1 değerlendirmek için (Jõesaar, Hein ve Hagger, 2012; McDavid, Cox ve Amorose, 2012; Wallhead, Hagger ve Smith, 2010) ve aynı zamanda antrenörü (Carpentier ve Mageau, 2013; González-Cutre ve diğ., 2014) değerlendirmek için kullanıldığı görülmüştür.

Araştırmanın amacı

Alan yazında sunulan araştırmaların sonuçları egzersiz ortamında algılanan özerklik desteğinin bireylerin düzenli fiziksel aktiviteye katılıma dair güdülenmesini olumlu yönde etkilediğini göstermektedir. Egzersiz ortamında farklı kaynaklardan alg1lanan özerklik desteğinin farklı kültürlerde geçerlik ve güvenirlik çalısmaları tespit edilmiş olmasına rağmen, ülkemizde egzersiz ortamında bu amaç için kullanılacak bir ölçeğe rastlanmamıştır. Bu çalışmanın amacı, Hagger ve diğ. tarafindan 2007 yılında geliştirilen Egzersizde Algılanan Özerklik Desteği Ölçeğinin hem öğretmen hem de arkadaşlar versiyonunun Türkçeye uyarlanması ve geçerlik ve güvenirliğinin incelenmesidir.

\section{Yöntem}

$\mathrm{Bu}$ bölümde araştırmaya katılan araştırma grubu hakkında genel bilgiler sunulacaktır. Sonrasında veri toplama araçları tanıtılacaktır. Türkçe uyarlaması yapılacak olan ölçeklerin çeviri aşamasından da bu bölümde bahsedilecektir. Son olarak verilerin toplanması ve analizi anlatılacaktır.

Araştırma grubu

Araştırmaya 2011-2012 eğitim öğretim yllında Ankara ilinde bulunan bir üniversitede okuyan öğrenciler gönüllü olarak katılmıştır. Bu araştırmada Egzersizde Öğretmenden Kaynaklanan Alg1lanan Özerklik Desteği Ölçeğini (EÖKAÖDÖ) 230 üniversite öğrencisi, Egzersizde Arkadaşlardan Kaynaklanan Algılanan Özerklik Desteği Ölçeğini (EAKAÖDÖ) ise 142 üniversite öğrencisi yanıtlamıştır. Araştırmaya katılan öğrencilere ait bilgiler Tablo 2'de sunulmuştur. 
Müftüler, M. (2016). Egzersizde Alg1lanan Özerklik Desteği Ölçeği: Türkçe geçerlik ve güvenirlik çalışması. International Journal of Human Sciences, 13(1), 2158-2169. doi:10.14687/ijhs.v13i1.3653

Tablo 2. Araştırmaya katılan öğrencilere ait bilgiler

\begin{tabular}{|c|c|c|c|c|c|c|c|}
\hline \multirow[b]{2}{*}{ Ölçek } & \multirow[b]{2}{*}{ Cinsiyet } & \multicolumn{2}{|c|}{ Frekans } & \multicolumn{4}{|c|}{ Yaş } \\
\hline & & $n$ & $\%$ & Min & Maks & Ort & SS \\
\hline EÖKAÖDÖ & Kadin & 114 & 49.6 & 19 & 31 & 22.54 & 1.85 \\
\hline & Erkek & 116 & 50.4 & 19 & 38 & 22.08 & 2.53 \\
\hline EAKAÖDÖ & Kadın & 81 & 57.0 & 19 & 31 & 22.74 & 2.07 \\
\hline & Erkek & 61 & 43.0 & 19 & 38 & 22.40 & 3.27 \\
\hline
\end{tabular}

EÖKAÖDÖ = Egzersizde Öğretmenden Kaynaklanan Algılanan Özerklik Desteği Ölçeği; EAKAÖDÖ = Egzersizde Arkadaşlardan Kaynaklanan Algılanan Özerklik Desteği Ölçeği; Min $=$ Minimum, Maks $=$ Maksimum, Ort $=$ Ortalama, $\mathrm{SS}=$ Standart sapma

Yukarıdaki tabloya göre Egzersizde Öğretmenden Kaynaklanan Alg1lanan Özerklik Desteği Ölçeğini yanıtlayan öğrencilerin 114’ü (\%49.6) kadın, 116’s1 (\%50.4) erkek; Egzersizde Arkadaşlardan Kaynaklanan Alg1lanan Özerklik Desteği Ölçeğini yantllayan öğrencilerin 81’i (\%57) kadın, 61’i (\%43) ise erkek öğrencidir.

Araşturmaya katılan kadın öğrencilerin yaş aralığ1 19 ila 31 yaş, erkek öğrencilerin yaş aralı̆̆1 ise 19 ila 38 yaş arasındadır. Buna göre Egzersizde Öğretmenden Kaynaklanan Algılanan Özerklik Desteği Ölçeğini yanıtlayan kadın öğrencilerin yaş ortalaması 22.54 (SS=1.85), erkek öğrencilerin yaş ortalamas1 ise 22.08 (SS=2.53)'dir. Egzersizde Arkadaşlardan Kaynaklanan Alg1lanan Özerklik Desteği Ölçeğini yanıtlayan kadın öğrencilerin yaş ortalaması 22.74 (SS=2.07), erkek öğrencilerin yaş ortalaması ise 22.40 (SS=3.27)'dır.

\section{Veri toplama arac1}

$\mathrm{Bu}$ araştırmada Hagger ve diğ. (2007) tarafindan geliştirilen Egzersizde Alg1lanan Özerklik Desteği Ölçeği kullanılmıştır. Bu ölçek, egzersiz ortamında bireyin kendisi için önemli başkalarından kaynaklanan algılanan özerklik desteğini değerlendirmektedir. Bu araştırmada ölçeğin iki versiyonu kullanılmıştır. Bunlardan biri Egzersizde Öğretmenden Kaynaklanan Algılanan Özerklik Desteği Ölçeği diğeri ise Egzersizde Arkadaşlardan Kaynaklanan Alg1lanan Özerklik Desteği Ölçeğidir.

Her iki ölçek 12 ifadeden oluşmaktadır ve tek boyutlu olduğu tespit edilmiştir (Hagger ve diğ., 2007). İfadeler tamamen katılmıyorum (1)'dan tamamen katıllyorum (7)'a doğru sıralanan yedili Likert üzerinden değerlendirilmektedir. Puanlama, ifadelere verilen değerlendirmelerin ortalaması alınarak yapılmaktadır. Ölçekten elde edilen yüksek puan, egzersizde algılanan özerklik desteğinin yüksek olduğunu göstermektedir.

Farklı kültürlerde uygulanan orijinal ölçeğin güvenilirlik kat sayısı Egzersizde Öğretmenden Kaynaklanan Algilanan Özerklik Desteği Ölçeği için .91 ile .93 arasında, Egzersizde Arkadaşlardan Kaynaklanan Algilanan Özerklik Desteği Ölçeği için ise .89 ile .94 olarak tespit edilmiştir (Hagger ve diğ., 2007).

\section{Çeviri aşaması}

Egzersizde Algılanan Özerklik Desteği Ölçeğinin Türkçeye uyarlama izni ölçeği geliştiren yazarlardan Martin S. Hagger'dan alındıktan sonra ölçekte yer alan ifadeler araştırmacı tarafindan Türkçeye çevrilmiştir. Eş zamanlı olarak başka bir İngilizce dil uzmanı tarafindan da çeviri işlemi yapılmıştır. Hem araşturmacının hem de İngilizce dil uzmanının orijinal ölçeklerin Türkçeye çevirileri karşılaştırılmıştır. Her iki çeviri arasında benzerlik olduğu tespit edilmiştir. Ardından alanında uzman bir spor bilimcisinin görüşleri alınmıştır. Son aşama olarak, her iki ölçekte yer alan ifadelerin anlaşılırlığının test edilmesi için Türkçeye çevrilmiş ölçekler Orta Doğu Teknik Üniversitesinde doktora eğitimi alan bir grup öğrenciye uygulanmıştır. İngilizce dil uzmanı, alanında uzman spor bilimcisi ve doktora öğrencilerinin görüssleri doğrultusunda her iki ölçeğin Türkçe formu oluşturulmuştur. 


\section{Verilerin toplanmasi}

$\mathrm{Bu}$ araştırma 2011 yllında Orta Doğu Teknik Üniversitesi Uygulamalı Etik Araştırma Merkezi tarafindan alınan etik kurul onayı (onay no: B.30.2.ODT.0.AH.00.00/126/126) ile aynı üniversitenin öğrencilerine uygulanmıştır. Araştırmaya katılan öğrencilerden kişisel bilgi istenmemiş olup ayrıca araştırmaya katulımın gönüllülük esas olduğu ve bilgilerinin sadece bilimsel amaçla kullanılacağı belirtilmiştir. Ayrıca kendilerine onam formu verilmiş ve bu formu okuduklarına dair imza atmaları istenmiştir. Ölçeklerin uygulanması yaklaşık 10 dakika sürmüştür.

Verilerin analizi

Öncelikle her iki ölçek için ortalama skor ve standart sapma gibi betimsel istatistik sonuçları incelenmiştir. Daha sonra her iki ölçeğin yapı geçerliğini incelemek için doğrulayıcı faktör analizi (DFA) bulguları incelenmiş ve iç güvenirliğini incelemek için Cronbach alfa değeri saptanmıştır.

\section{Bulgular}

$\mathrm{Bu}$ bölümde elde edilen verilerin betimleyici analiz bulgularına yer verilecektir. Daha sonra sırasıyla Türkçe uyarlaması yapılan ölçeklerin geçerlik ve güvenirlik bulguları sunulacaktır.

Betimleyici analiz bulgular1

Betimleyici analiz bulguları Tablo 3’te sunulmuştur. Buna göre Egzersizde Öğretmenden Kaynaklanan Algılanan Özerklik Desteği Ölçeğinden elde edilen puanların ortalaması 4.56 (SS=1.49)'dır. Kadınların bu ölçekten elde ettikleri puanların ortalamas1 4.70 (SS=1.45), erkeklerin puan ortalamas1 ise 4.42 (SS=1.52)'dir. Egzersizde Arkadaşlardan Kaynaklanan Alg1lanan Özerklik Desteği Ölçeğinden elde edilen puanların ortalaması ise 4.78 (SS=1.02)'dir. Kadınların bu ölçekten aldıkları puanların ortalaması 4.78 (SS=0.97), erkeklerin puan ortalaması da 4.78 (SS=1.08)'dir.

Tablo 3. Egzersizde Algılanan Özerklik Desteği Ölçeği betimleyici analiz ve varsayım analizi bulgular1

\begin{tabular}{|c|c|c|c|c|c|c|}
\hline Ölçek & Cinsiyet & $n$ & Min & Maks & Ort & SS \\
\hline \multicolumn{2}{|c|}{ EÖKAÖDÖ } & 230 & 1.00 & 7.00 & 4.56 & 1.49 \\
\hline & Kadın & 114 & 1.00 & 7.00 & 4.70 & 1.45 \\
\hline & Erkek & 116 & 1.00 & 7.00 & 4.42 & 1.52 \\
\hline \multicolumn{2}{|c|}{ EAKAÖDÖ } & 142 & 1.00 & 6.92 & 4.78 & 1.02 \\
\hline & Kadın & 81 & 2.33 & 6.58 & 4.78 & 0.97 \\
\hline & Erkek & 61 & 1.00 & 6.92 & 4.78 & 1.08 \\
\hline
\end{tabular}

EÖKAÖDÖ = Egzersizde Öğretmenden Kaynaklanan Algılanan Özerklik Desteği Ölçeği; EAKAÖDÖ = Egzersizde Arkadaşlardan Kaynaklanan Algılanan Özerklik Desteği Ölçeği; Min = Minimum; Maks = Maksimum; Ort = Ortalama; SS = Standart sapma

Geçerlik analizi bulgulanı

Ölçeğin yapı geçerliğini incelemek için doğrulayıcı faktör analizi (DFA) kullanılmıştır. DFA, alan yazında daha önceden doğruluğu tespit edilmiş bir modelin farklı bir örneklem üzerinde doğruluğunun tespiti için kullanılan bir analiz türüdür (Sümer, 2000). DFA'da önerilen model ile elde edilen verinin uyumunu değerlendirmek için genel uyum indeksleri $\left(\chi^{2} /\right.$ sd oranı ve $p$ değeri), yaklaşık hataların ortalama karekökü (RMSEA değeri), karşılaştırmalı uyum indeksleri (CFI ve NFI değerleri) ve mutlak uyum indeksleri (SRMR ve GFI değerleri) incelenir. Her iki ölçeğin uyum ölçütleri, ölçeklerin DFA değerleri ve referans değerleri Tablo 4'te sunulmuştur. 
Müftüler, M. (2016). Egzersizde Alg1lanan Özerklik Desteği Ölçeği: Türkçe geçerlik ve güvenirlik çalışması. International Journal of Human Sciences, 13(1), 2158-2169. doi:10.14687/ijhs.v13i1.3653

Tablo 4. Doğrulayıcı faktör analizi bulguları ve referans değerler

\begin{tabular}{|c|c|c|c|c|}
\hline \multirow{2}{*}{$\begin{array}{l}\text { Uyum } \\
\text { ölçütü }\end{array}$} & \multicolumn{2}{|c|}{ Ölçek değeri } & \multirow[b]{2}{*}{ Referans değer } & \multirow[b]{2}{*}{ Kaynakça } \\
\hline & EÖKAÖDÖ & EAKAÖDÖ & & \\
\hline$\chi^{2} / \mathrm{sd}$ & 2.33 & 1.73 & $\chi^{2} / s d \leq 3$ & (Bayram, 2010) \\
\hline$p$ & .001 & .002 & $\leq .05$ & (Bayram, 2010) \\
\hline RMSEA & .076 & .072 & $\leq .08$ & (Hu ve Bentler, 1999) \\
\hline CFI & .978 & .973 & $\geq .95$ & (Hu ve Bentler, 1999) \\
\hline NFI & .963 & .941 & $\geq .95$ & (Hu ve Bentler, 1999) \\
\hline SRMR & .035 & .042 & $<.05$ & (Byrne, 2001) \\
\hline GFI & .932 & .920 & $\geq .95$ & (Byrne, 2001) \\
\hline
\end{tabular}

EÖKAÖDÖ = Egzersizde Öğretmenden Kaynaklanan Algılanan Özerklik Desteği Ölçeği;

EAKAÖDÖ = Egzersizde Arkadaşlardan Kaynaklanan Algılanan Özerklik Desteği Ölçeği;

$\chi^{2}=$ Ki-kare; sd = serbestlik derecesi; RMSEA = yaklaşı hataların ortalama karekökü;

$\mathrm{CFI}=$ karşılaştırmalı uyum indeksi; NFI = normlandırılmış uyum indeksi;

SRMR = standardize edilmiş ortalama hataların karekökü; GFI = iyilik uyum indeksi

Egzersizde Öğretmenden Kaynaklanan Algılanan Özerklik Desteği Ölçeği $\left(\chi^{2} / \mathrm{sd}=2.33, p\right.$ $\leq .05)$ ve Egzersizde Arkadaşlardan Kaynaklanan Alg1lanan Özerklik Desteği Ölçeğinin $\left(\chi^{2} / \mathrm{sd}=\right.$ $1.73, p \leq .05)$ genel uyum indeksleri referans değerlere göre iyi uyum göstermiştir (Bayram, 2010).

Egzersizde Öğretmenden Kaynaklanan Alg1lanan Özerklik Desteği Ölçeği (RMSEA = .076) ve Egzersizde Arkadaşlardan Kaynaklanan Alg1lanan Özerklik Desteği Ölçeğinin (RMSEA = .072) yaklaşık hataların ortalama karekökü değerleri de referans değere göre iyi uyum göstermiştir (Hu ve Bentler, 1999).

Egzersizde Öğretmenden Kaynaklanan Algılanan Özerklik Desteği Ölçeğinin karşılaştırmalı uyum indeksleri $(\mathrm{CFI}=.978$; $\mathrm{NFI}=.963)$ referans değerlere göre uygun bulunmuştur (Hu ve Bentler, 1999). Egzersizde Arkadaşlardan Kaynaklanan Algılanan Özerklik Desteği Ölçeğinin (CFI $=.973$ ) CFI değeri referans değere uygundur. Ancak NFI değeri ise .941 ile çok az bir farkla referans değerlerin altında bulunmuştur (Hu ve Bentler, 1999).

Egzersizde Öğretmenden Kaynaklanan Algılanan Özerklik Desteği Ölçeği (SRMR = .035; GFI $=.932)$ ve Egzersizde Arkadaşlardan Kaynaklanan Algılanan Özerklik Desteği Ölçeğinin $(\mathrm{SRMR}=.042 ; \mathrm{GFI}=.920)$ mutlak uyum indeksleri referans değere yakın hesaplanmıştır (Byrne, 2001).

Güvenirlik analizi bulgulanı

$\mathrm{Bu}$ araştırmada Türkçe uyarlaması yapılan ölçeklerin iç güvenirliği için Cronbach alfa kat sayısı hesaplanmıştır. Elde edilen bulgular doğrultusunda Egzersizde Öğretmenden Kaynaklanan Alg1lanan Özerklik Desteği Ölçeğinin Cronbach alfa değeri .96, Egzersizde Arkadaşlardan Kaynaklanan Algilanan Özerklik Desteği Ölçeğinin Cronbach alfa değeri ise .93 olarak hesaplanmıştır. Bu değerler oldukça yüksek değerlerdir (Field, 2009). Buna göre her iki ölçeğin iç güvenirliğinin yüksek olduğu tespit edilmiştir.

\section{Tartışma}

Bu araştırmada özgün adı "Perceived Autonomy Support Scale for Exercise Settings" olan Egzersizde Algılanan Özerklik Desteği Ölçeğinin hem öğretmen hem de arkadaşlar versiyonunun Türkçeye uyarlanması ve geçerlik ve güvenirliğinin incelenmesi amaçlanmıştır. Alan yazında bu ölçeğin farklı kültürlerde kullanıldığı (Hagger ve diğ., 2007), farklı dillere çevrildiği (Gillet ve diğ., 2010b) ve farklı kaynaklardan algılanan özerklik desteğinin (Hagger ve diğ., 2009; Gillet ve diğ., 2010a) incelendiği araştırmaların olduğu görülmektedir. Ancak Türkiye'de beden eğitimi, spor ve egzersiz alanında algılanan özerklik desteğini ölçen bir ölçüm aracının olmadığı tespit edilmiştir. Bu amaçlar doğrultusunda Hagger ve diğ. (2007) tarafindan geçerliği ve güvenirliği tespit edilen ölçek 
Müftüler, M. (2016). Egzersizde Alg1lanan Özerklik Desteği Ölçeği: Türkçe geçerlik ve güvenirlik çalışması. International Journal of Human Sciences, 13(1), 2158-2169. doi:10.14687/ijhs.v13i1.3653

Türkçeye çevrilmiş ve çevirisi tamamlanan ölçekler bir grup üniversite öğrencisine uygulanmıştır. Ölçeğin yap1 geçerliği ve iç güvenirliği incelenmiştir.

Ölçeğin yapı geçerliğini incelemek için gerçekleştirilen doğrulayıcı faktör analizi bulguları incelendiğinde, her iki ölçeğin tek boyutlu yapısının elde edilen veri ile uyum gösterdiği bulunmuştur. Alan yazında her iki ölçeğin farklı kültürlerde uygulandığ1 ve yap1 geçerliğinin test edildiği görülmektedir (Hagger ve diğ., 2007). Hagger ve diğ. (2007)'nin araştırmasinda Egzersizde Öğretmenden Kaynaklanan Algılanan Özerklik Desteği Ölçeğinin yap1 geçerliği bulguları iyi uyum göstermektedir $\left(\chi^{2} / \mathrm{sd}=2.22, p<.01, \mathrm{CFI}=.966, \mathrm{SRMR}=.036, \mathrm{RMSEA}=.053\right)$. Hagger ve diğ. (2007)'nin bulguları Türkçeye uyarlanan ölçeğin DFA bulguları ile benzerlik göstermektedir (bkz. Tablo 4).

Egzersizde Arkadaşlardan Kaynaklanan Algılanan Özerklik Desteği Ölçeğinin yapı geçerliği İngiltere, Estonya ve Macaristan gibi farklı kültürlerde test edilmiştir (Hagger ve diğ., 2007). Elde edilen sonuçlara göre bu ölçeğin farklı kültürlerdeki yapı geçerliği bulguları iyi uyum göstermiştir (İngiltere örneklemi için: $\chi^{2} / \mathrm{sd}=2.07, \mathrm{CFI}=.949$, SRMR $=.052$, RMSEA $=.071$; Estonya örneklemi için: $\chi^{2} / \mathrm{sd}=1.68, \mathrm{CFI}=.969$, SRMR $=.043$, RMSEA $=.051$; Macaristan örneklemi için: $\left.\chi^{2} / \mathrm{sd}=1.94, \mathrm{CFI}=.948, \mathrm{SRMR}=.051, \mathrm{RMSEA}=.063\right)$.

Hagger ve dĭg. (2007)'nin elde ettiği bulgular ile Türkçeye uyarlanan Egzersizde Arkadaşlardan Kaynaklanan Algılanan Özerklik Desteği Ölçeğinin yapı geçerliği bulguları yakınlık göstermektedir (bkz. Tablo 4). Diğer kültürlerde uygulanan ölçek ile Türkçeye uyarlanan ölçeğin yap1 geçerliği bulguları arasındaki farklılık örneklem büyüklüğüne göre farklılık göstermiş olabilir çünkü uyum indeksleri verileri örneklemin büyüklüğüne göre değişmektedir (Byrne, 2001). Ancak yine de her iki ölçeğin yapı geçerliği bulguları alan yazındaki bulgular ile benzerlik göstermektedir.

$\mathrm{Bu}$ araştırmada yapı geçerliğinin yanı sıra, Türkçeye uyarlanan ölçeklerin iç güvenirliği de test edilmiştir. Elde edilen verilere göre Türkçeye uyarlanan ölçeklerin iç güvenirliği oldukça yüksek çıkmıştır (EÖKAÖDÖ = .96; EAKAÖDÖ = .93). Alan yazında her iki ölçeğin güvenirlik analizi farklı kültürlerde de test edilmiştir. Farklı kültürlerde yapılan araştırmalarda Egzersizde Öğretmenden Kaynaklanan Alg1lanan Özerklik Desteği Ölçeğinin iç güvenirliği .82 ile .95 arasında çıkmıştır ve oldukça yüksektir (Hagger ve diğ., 2005; 2007). Egzersizde Arkadaşlardan Kaynaklanan Algılanan Özerklik Desteği Ölçeğinin iç güvenirliği ise .89 ile .94 arasında çıkmıştır ve oldukça yüksektir (Hagger ve diğ., 2007; 2009). Bu araştırmada Türkçeye uyarlanan ölçeklerin iç güvenirlik bulguları alan yazında yapılan farklı kültürlerdeki araştırmaların bulguları ile benzerlik göstermektedir. Buna göre Türkçeye uyarlanan ölçeklerin iç güvenirliği yüksek olduğu söylenebilir. $\mathrm{Bu}$ araştırma sunulan geçerlik ve güvenirlik bulgularının yanı sıra bazı sınırllıklar da içermektedir. $\mathrm{Bu}$ araştırmada ölçekler bir grup üniversite öğrencisine uygulanmıştır. Aynı zamanda bu araştırmanın okul çağı öğrencilerine (ilköğretim, ortaokul ve lise öğrencileri gibi) uygulanması ve bu örneklemlerdeki yap1 geçerliğinin ve güvenirliğinin tespit edilmesi önerilmektedir. Ayrıca bu araşturmada sadece öğrencilerin öz bildirimleri dikkate alınmıştur. Ancak öğretmen ve/veya arkadaşların özerklik desteği davranışları test edilmemiştir. Son yıllarda alan yazında özellikle öğretmenlerin psikolojik ihtiyaç-destekleyici davranışları gözlem yoluyla tespit edilmeye başlanmıştır (Haerens ve diğ., 2013). Egzersizde algılanan özerklik desteğinin ölçülebilmesi için sadece ölçek kullanımının yanı sıra egzersiz ortamlarının özerklik desteği açısından gözlemlenmesi de önerilmektedir.

Sonuç olarak bu araştırmadan elde edilen bulgular göz önünde bulundurarak Egzersizde Algılanan Özerklik Desteği Ölç̧eğinin hem öğretmen hem de arkadaşlar versiyonunun Türkçe yap1 geçerliği ve güvenirliği tespit edilmiş olup alan yazında kullanılabileceği önerilmektedir. 
Müftüler, M. (2016). Egzersizde Alg1lanan Özerklik Desteği Ölçeği: Türkçe geçerlik ve güvenirlik çalışması. International Journal of Human Sciences, 13(1), 2158-2169. doi:10.14687/ijhs.v13i1.3653

\section{Kaynakça}

Amorose, A.J. ve Anderson-Butcher, D. (2007). Autonomy-supportive coaching and self-determined motivation in high school and college athletes: A test of self-determination theory. Psychology of Sport and Exercise, 8(5), 654-670.

Andersen, S. (2000). Fundamental human needs: Making social cognition relevant. Psychological Inquiry, 11(4), 269-276.

Aydoğdu, C. (2009). Yabancı dil öğretiminde otonom öğrenme: Neden ve nasıl? Uluslar arası Sosyal Araștirmalar Dergisi, 2(8), 68-74.

Baard, P.P., Deci, E.L. ve Ryan, R.M. (2004). Intrinsic need satisfaction: A motivational basis of performance and well-being in two working settings. Journal of Applied Social Psychology, 34(10), 2045-2068.

Balçıkanlı, Ç. (2008). Fostering learner autonomy in EFL classrooms. Kastamonu Eğitim Dergisi, 16(1), 277-284.

Barkoukis, V., Hagger, M.S., Lambropoulos, G. ve Tsorbatzoudis, H. (2010). Extending the transcontextual model in physical education and leisure-time contexts: Examining the role of basic psychological need satisfaction. British Journal of Educational Psychology, 80(4), 647-670.

Bayram, N. (2010). Yapısal esittlik modellemesine giriș: AMOS uygulamalar. İstanbul: Ezgi Kitabevi.

Black, A.E. ve Deci, E.L. (2000). The effects of instructors' autonomy support and students' autonomous motivation on learning organic chemistry: A test of self-determination theory persective. Science Education, 84, 740-756.

Byrne, B.M. (2001). Structural equation modeling with AMOS: Basic concepts, applications, and programming. Mahwah, N.J.: Lawrance Erlbaum.

Carpentier, J. ve Mageau, G.A. (2013). When change-oriented feedback enhances motivation, wellbeing and performance: A look at autonomy-supportive feedback in sport. Psychology of Sport and Exercise, 14(3), 423-435.

Cheon, S.H., Reeve, J. ve Moon, I.S. (2012). Experimentally based, longitudinally designed, teacherfocused intervention to help physical education teachers be more autonomy supportive toward their students. Journal of Sport and Exercise Psychology, 34(3), 365-396.

Deci, E.L. ve Ryan, R.M. (1985). Intrinsic motivation and self-determination in buman behaviour. New York: Plenum Publishing Company.

Deci, E.L. ve Ryan, R.M. (1987). The support of autonomy and the control of behavior. Journal of Personality and Social Psychology, 53(6), 1024-1037.

Edmunds, J.K., Ntoumanis, N. ve Duda, J.L. (2006). A test of self-determination theory in the exercise domain. Journal of Applied Social Psychology, 36(9), 2240-2265.

Field, A. (2009). Discovering statistics using SPSS (and sex and drugs and rock ' $n$ ' roll) ( $3^{\text {rd }}$ ed.). London, UK: Sage

Gillet, N., Vallerand, R.J., Amoura, S. ve Baldes, B. (2010a). Influence of coaches' autonomy support on athletes' motivation and sport performance: A test of hierarchical model of intrinsic and extrinsic motivation. Psychology of Sport and Exercise, 11(2), 155-161.

Gillet, N., Vallerand, R.J., Paty, E., Gobance, L. ve Berjot, S. (2010b). French validation and adaptation of the perceived autonomy suuport scale for exercise settings to the sport context. International Journal of Sport and Exercise Psychology, 8(2), 117-128.

González-Cutre, D., Ferriz, R., Beltran-Carillo, V.J., Andres-Fabra, J.A., Montero-Carretero, C., Cervello, E. ve Moreno-Murcia, J.A. (2014). Promotion of autonomy for participation in physical activity: A study based on the trans-contextual model of motivation. Educational Psychology, 34(3), 367-384.

Grolnick, W. ve Ryan, R.M. (1987). Autonomy in children's learning: An experimental and individual difference investigation. Journal of Personality and Social Psychology, 52, 890-898.

Guay, F., Boggiano, A. ve Vallerand, R. (2001). Autonomy support, intrinsic motivation and perceived competence: Conceptual and empirical linkages. Personality and Social Psychology Bulletin, 27(6), 643-650. 
Müftüler, M. (2016). Egzersizde Alg1lanan Özerklik Desteği Ölçeği: Türkçe geçerlik ve güvenirlik çalışması. International Journal of Human Sciences, 13(1), 2158-2169. doi:10.14687/ijhs.v13i1.3653

Güvenç, H. (2011). Sınıf öğretmenlerinin özerklik destekleri ve mesleki özyeterlik algıları. Kuram ve Uygulamada Eğitim Yönetimi [Educational Administration: Theory and Practice], 17(1), 99-116.

Haerens, L., Aelterman, N., Van den Berghe, L., De Meyer, J., Soenens, B. ve Vansteenkiste, M. (2013). Observing physical education teachers' need-supportive interactions in classroom settings. Journal of Sport \& Exercise Psychology, 35(1), 3-17.

Hagger, M.S., Chatzisarantis, N.L.D., Barkoukis, V., Wang, C.K.J. ve Baranowski, J. (2005). Perceived autonomy support in physical education and leisure-time physical activity: A cross-cultural evaluation of the Trans-Contextual Model. Journal of Educational Psychology, 97(3), 379-390.

Hagger, M.S., Chatzisarantis, N.L.D., Hein, V., Pihu, M., Soos, I. ve Karsai, I. (2007). The perceived autonomy support scale for exercise settings (PASSES): Development, validity, and crosscultural invariance in young people. Psychology of Sport and Exercise, 8(5), 632-653.

Hagger, M.S., Chatzisarantis, N.L.D., Hein, V., Soos, I., Karsai, I., Lintunen, T. ve Leemans, S. (2009). Teacher, peer and parent autonomy support in physical education and leisure-time physical activity. A trans-contextual model of motivation in four nations. Psychology and Health, 24(6), 689-711.

Hu, L. ve Bentler, P.M. (1999). Cutoff criteria for fit indexes in co-variance structure analysis: Conventional criteria versus new alternatives. Structural Equation Modeling: A Multidisciplinary Journal, 6(1), 1-55.

Jõesaar, H., Hein, V. ve Hagger, M.S. (2012). Youth athletes' perception of autonomy support from the coach, peer motivational climate and intrinsic motivation in sport setting: One-year effects. Psychology of Sport and Exercise, 13(3), 257-262.

Lim, B.S.C. ve Wang, C.K.J. (2009). Perceived autonomy support, behavioural regulationsin physical education and physical activity intention. Psychology of Sport and Exercise, 10(1), 52-60.

Mageau, G. ve Vallerand, R.J. (2003). The coach-athlete relationship: A motivation model. Journal of Sports Sciences, 21(11), 883-904.

McDavid, L., Cox, A.E. ve Amorose, A.J. (2012). The relative roles of physical education teachers and parents in adolescents' leisure-time physical activity motivation and behavior. Psychology of Sport and Exercise, 13(2), 99-107.

Moreno, J.A., Parra, N. ve González-Cutre, D. (2008). Influencia del apoyo a la autonomía, las metas sociales y la relación con los demás sobre la desmotivación en educación física [Influence of autonomy support, social goals and relatedness on amotivation in physical education classes]. Psicothema, 20(4), 636-641.

Moustaka, F.C., Vlachopoulos, S.P., Kabitsis, C. ve Theodorakis, Y. (2012). Effects of an autonomysupportive exercise instructing style on exercise motivation, psychological well-being, and exercise attendance in middle-aged women. Journal of Physical Activity and Health, 9(1), 138-150.

Müftüler, M. ve İnce, M.L. (2015). Use of trans-contextual model based physical acivity course in developing leisure-time physical activity behavior of university students. Perceptual and Motor Skills, 121(1), 31-55.

Oğuz, A. (2013). Öğretmenlerin öğrenen özerkliğinin desteklenmesine ilişkin görüşleri. International Journal of Human Sciences, 10(1), 1273-1297.

Özgüngör, S. (2006) Üniversite öğrencilerinin amaç tarzlarının ve öğretmenlerinin özerklik destekleyici davranışlarına ilişkin algılarının öğrencinin motivasyonu ve akademik davranışlarıyla ilişkisi. Türk Psikolojïk Danıșma ve Rebberlik Dergisi, 3(25), 27-36.

Puente, R. ve Anshel, M.H. (2010). Exercisers' perceptions of their fitness instructor's interacting style, perceived competence, and autonomy as a function of self-determined regulation to exercise, enjoyment, affect, and exercise frequency. Scandinavian Journal of Psychology, 51(1), 3845.

Reeve, J. (2002). Self-determination theory applied to educational settings. Edward L. Deci ve Richard M. Ryan (Ed.) Handbook of self-determination research içinde, (183-203). Rochester, NY: The University of Rochester Press. 
Müftüler, M. (2016). Egzersizde Alg1lanan Özerklik Desteği Ölçeği: Türkçe geçerlik ve güvenirlik çalışması. International Journal of Human Sciences, 13(1), 2158-2169. doi:10.14687/ijhs.v13i1.3653

Reeve, J. (2006). Teachers as facilitators: What autonomy-supportive teachers do and why their students benefit. Elementary School Journal, 106, 225-236.

Reeve, J. ve Jang, H. (2006). What teachers say and do to support students' autonomy during learning activity. Journal of Educational Psychology, 98(1), 209-218.

Reeve, J., Bolt, E. ve Cai, Y. (1999). Autonomy-supportive teachers: How they teach and motivate students. Journal of Educational Psychology, 91(3), 537-548.

Ryan, R.M. ve Deci, E.L. (2000). Self-determination theory and the facilitation of intrinsic motivation, social development, and well-being. American Psychologist, 55(1), 68-78.

Sert, N. (2006). EFL Student Teachers'Learning Autonomy. The Asian EFL Journal Quarterly, 8(2), 180-201.

Sert, N. (2007). Öğrenen özerkliğine ilişkin bir ön çalışma. İlköğretim online, 6(1), 180-196.

Shen, B. (2010). How can perceived autonomy support influence enrollment in elective physical education? A prospective study. Research Quarterly for Exercise and Sport, 81(4), 456-465.

Shen, B., McCaughtry, N., Martin, J. ve Fahlman, M. (2009). Effects of teacher autonomy support and students' autonomous motivation on learning in physical education. Research Quarterly for Exercise and Sport, 80(1), 44-53.

$\mathrm{Su}$, Y.L. ve Reeve, J. (2011). A meta-analysis of the effectiveness of intervention programs designed to support autonomy. Educational Psychology Review, 23(1), 159-188.

Sümer, N. (2000). Yapısal eşitlik modelleri: Temel kavramlar ve örnek uygulamalar. Türk Psikoloji Yazllar, 3(6), 49-74.

Üstünoğlu, E. (2009). Dil öğrenmede özerklik: Öğrenciler kendi öğrenme sorumluluklarını üstlenebiliyorlar mı? Eğitimde Kuram ve Uygulama, 5(2), 148-169.

Wallhead, T.L., Hagger, M.S. ve Smith, D.T. (2010). Sport education and extracurricular sport participation: An examination using the trans-contextual model of motivation. Research Quarterly for Exercise and Sport, 81(4), 442-455

Williams, G.C., Cox, E.M., Kouides, R. ve Deci, E.L. (1999). Presenting the facts about smoking to adolescents: The effects of an autonomy supportive style. Archives of Pediatrics and Adolescent Medicine, 153(9), 959-964.

\section{Extended English Abstract}

Purpose

Self-Determination Theory (SDT) is a motivation theory that explains the motivational processes of individuals' behaviors (Deci \& Ryan, 1985). According to SDT, the basic psychological needs would be satisfied in order to form any behavior. The basic psychological needs are the competence, relatedness, and autonomy needs (Deci \& Ryan, 1987). Competence need refers to the capacity to feel efficient toward behavior and making effective communication toward the environment. Relatedness need means to be in connected with significant others and to feel belong to a social environment. Autonomy need corresponds to the desire to choose own actions and decisions and the feeling of being self-endorsed. Autonomy support means an interpersonal support to establish and develop autonomy needs, personal interest, purpose and value for encouraging intrinsic motivation (Reeve \& Jang, 2006). Perceived autonomy support is the degree to which an individual perceives autonomy support from significant others (Deci \& Ryan, 1987). The perceived autonomy support from significant others has been widely studied in general education, physical education (PE), sport, and exercise, work, parenting, health care, and psychotherapy. The sources of autonomy support have varied in different settings. The most significant source of autonomy support in physical education setting is the teacher (Hagger et al., 2007), in sport setting is the coach (Mageau \& Vallerand, 2003), and in exercise setting is the exercise instructor (Moustaka et al., 2012), the peers and parents as well (Hagger et al., 2009). However, the overall effect of perceived autonomy 
support from significant others were quite well established. The perceived autonomy support affects optimal learning and participation in PE (Shen et al., 2009), increases intrinsic motivation toward physical activity (PA) participation (Edmunds et al., 2006) and increased sport performance (Amorose \& Anderson-Butcher, 2007). For Turkish context, although more studies have been conducted about perceived autonomy support in education setting, there is a need for examining perceived autonomy support in exercise setting. In PE, sport, and exercise setting, Hagger et al. (2007) developed and validated a questionnaire (Perceived Autonomy Support Scale in Exercise Setting - PASSES) to measure perceived autonomy support from PE teacher, peers, and parents. Although this scale was translated and adapted into different languages (Gillet et al., 2010b), there is no scale to measure perceived autonomy support from significant others in exercise setting in Turkish context. Therefore, the purpose of this study was to examine the validity and reliability of PASSES from teacher and from peers in Turkish context.

\section{Method}

This study was conducted with volunteer university students in a university in Ankara. In this study, 230 university students (female: $n=116, M_{\text {age }}=22.54$; male: $n=114, M_{\text {age }}=22.08$ ) completed PASSES from teacher, and 142 university students (female: $n=81, M_{\text {age }}=22.74$; male: $n$ $\left.=61, M_{\text {age }}=22.40\right)$ completed PASSES from peers. PASSES from teacher and from peers were used for data collection. Each scale has 12 items with a unidimension structure. The items were rated on a 7-point Likert type scale from 1 representing totally disagree to 7 totally agree (Hagger et al., 2007). The author first got permission to use the scale from Martin S. Hagger who developed it, then two independent experts translated each scale from English to Turkish. The translated versions were examined by another sport science expert and by doctoral students to analyze the appropriateness of translated versions with Turkish language. Each scale was analyzed by using descriptive statistics, by using confirmatory factor analysis (CFA) to determine validity, and by using Cronbach alpha value to determine reliability.

\section{Results}

Confirmatory factor analysis results showed good fit indexes for PASSES from instructor $\left(\chi^{2} / \mathrm{df}=2.33 ; p=.001 ; \mathrm{RMSEA}=.076 ; \mathrm{CFI}=.978 ; \mathrm{NFI}=.963 ; \mathrm{SRMR}=.035 ; \mathrm{GFI}=.932\right)$ and for PASSES from peers $\left(\chi^{2} / \mathrm{df}=1.73 ; p=.002\right.$; RMSEA $=.072$; CFI $=.973$; NFI $=.941$; SRMR $=$ .042 ; GFI $=.920)$. The reliability analyses showed high values for reliability of each scale $(\alpha=.96$ for PASSES from teacher; $\alpha=.93$ for PASSES from peers).

\section{Discussion and conclusion}

This study examined the validity and reliability of PASSES from teacher and from peers in Turkish context. The validity analyses for each scale showed good fit indexes in Turkish context. The validity results were also supported by Hagger et al.'s (2007) study which showed good fit scores of each scale in different cultures. The reliability analyses also showed high reliability scores for each scale. These results were also consistent with previous studies (Hagger et al., 2005; 2007; 2009). Although this study has some limitation, it was suggested that observational studies should be used to measure teachers' and/or peers autonomy supportive behaviors in exercise setting (Haerens et al., 2013). Overall, it was suggested that each scale can be used in Turkish context. 